\title{
Retrospective assessment of long-term conservation management of elephants in Addo Elephant National Park, South Africa
}

\author{
Anna M. Whitehouse and Graham I. H. Kerley
}

\begin{abstract}
The elephant population of South Africa's Addo Elephant National Park increased in number from 11 elephants when the park was created in 1931, to 284 elephants in 1998. We studied management records throughout this period in conjunction with demographic data, enabling retrospective assessment of the long-term impacts of management actions. Problem animal control during the 1930s left no sexually mature bulls in the population for a period of 9 years, hindering the population's initial recovery. Population growth prior to 1954 was also limited by high mortality: between 1931 and 1954 inadequate fencing allowed elephants to stray outside their protected area resulting in elephants being shot by farmers or dying from collisions with trains. Secure elephant-proof fencing was constructed in 1954
\end{abstract}

Subsequently, there was a significant decrease in mortality (from $5.0 \%$ to $1.2 \%$ ) and an increase in population growth (from $3.2 \%$ to $6.1 \%$ ). However, evidence suggests that confinement might have had a negative impact on survival and social behaviour of adult males. We suggest that the concepts of social carrying capacities and behavioural conservation of populations need to be incorporated into management. The case studies described here highlight the importance of treating conservation management and research as necessary partners, and monitoring should be an integral part of any management plan.

Keywords Addo, carrying capacity, conservation management, elephant, population, South Africa.

\section{Introduction}

Conservation managers are constantly faced with decisions on how best to manage the species and populations under their care. However, since natural ecosystems are complex (Bell, 1983), management decisions must inevitably be based on a series of assumptions, given the best available knowledge. As a result, the consequences of management intervention, particularly in the long-term, are often unknown. It is therefore imperative that wildlife conservation should combine management with research under a system of adaptive management (Dublin \& Taylor, 1996), so that lessons are learned from choices made today, enabling tomorrow's managers to make more informed decisions (Macnab, 1983).

Despite the fact that African elephants Loxodonta africana are relatively well studied in comparison to many other species, we still cannot claim to be able to fully understand them and cannot always accurately predict how

Anna M. Whitehouse ${ }^{1}$ (Corresponding author) and Graham I. H. Kerley Terrestrial Ecology Research Unit, Department of Zoology, University of Port Elizabeth, PO Box 1600, Port Elizabeth, 6000, South Africa.

${ }^{1}$ Present address: Addo Elephant National Park, PO Box 52, Addo 6105, South Africa. E-mail: awhitehouse@ifaw.org

Received 11 June 2001. Revision requested 24 October 2001 Accepted 27 February 2002. a population will react to management intervention. This may lead to inappropriate and futile management decisions. For example, current methods of dealing with human-elephant conflicts usually involve removal of 'problem elephants'. However, evidence now suggests that populations may have a 'problem component', and as individuals responsible for conflicts are removed, others take their place (Hoare, 2001).

African elephants are long lived, and so the repercussions of management actions on an elephant population may not be apparent for a decade or longer. For example, approximately 10 years after the introduction of juvenile orphan elephants into South Africa's Pilanesberg National Park, these elephants began killing white rhinoceros Ceratotherium simum (Slotow et al., 2000). With hindsight, it is apparent that this resulted from the elephants growing up in the absence of a normal social structure and without adult supervision and discipline (Garai, 1997; Slotow et al., 2000). Consequently, it is now recommended that elephants should only be translocated as intact family units (Garai, 1997).

In order to assess the impacts of applied management on an elephant population, long-term data are required. Important lessons can be learnt with hindsight, and so the consequences of past management practices should be examined wherever possible to increase our understanding and avoid repetition of past mistakes (Waithaka, 1997). 
In this paper we make a retrospective assessment of the conservation management of the elephant population within Addo Elephant National Park (AENP), South Africa. AENP ( $\left.33^{\circ} 30^{\prime} \mathrm{S}, 2^{\circ} 45^{\prime} \mathrm{E}\right)$, situated c. $60 \mathrm{~km}$ north-east of Port Elizabeth in the Eastern Cape Province, was established in 1931 to preserve the last remaining elephants in the region. Although elephants in this area were relatively abundant in the early 1900s (Hall-Martin, 1992), conflicts with farmers resulted in an attempt to exterminate the entire population (Hoffman, 1993). However, this operation was aborted prior to completion (Hoffman, 1993), and 11 elephants survived to form AENP's founder population (Whitehouse \& Hall-Martin, 2000).

The history of the Addo elephant population between 1931 and 1998 has been reconstructed by tracing individual elephant life histories throughout this period (Whitehouse \& Hall-Martin, 2000). The resulting longterm data-set includes dates of birth and death of every elephant in the population since the establishment of the park, annual population sizes, and maternal family trees from 1931 to 1998. These demographic data are studied in conjunction with records of the management of the population, obtained from the unpublished archives of the South African National Parks, throughout the history of the park. Three management case studies are described, and the impacts of problem animal control and the fencing of the area are evaluated.

\section{Management case studies}

\section{Problem animal control}

On two occasions during 1932 an adult bull destroyed one of the windmills used for pumping water within the park, necessitating costly repairs, and the animal responsible was shot. In 1937 another adult bull, named Pretorius, killed an elephant calf and then later in same the year he killed one of the park's rangers. Consequently, this bull was also shot.

The destruction of these two bulls left no sexually mature bulls in the population. There were just three males in the founder population of eleven elephants in 1931, and only two of these were adults, the third being a young male calf called HT. When Pretorius was shot in 1937, HT was not yet sexually mature, and in 1940, before reaching sexual maturity, he was hit and killed by a train whilst roaming outside the park.

There were 18 births during 1931-1938, when Pretorius' last offspring were born, and population size at the end of 1938 was 25 animals. However, the effective population size was zero. A 9 year hiatus in recruitment followed, during which population size decreased to 18 . The first male calves born in the early 1930s reached sexual maturity in 1946, and recruitment resumed in 1948 (elephant gestation period is 22 months).

\section{Lack of a secure boundary fence, 1931-1954}

Between 1931 and 1954 AENP was not surrounded by a secure boundary fence (Pringle, 1948; Pringle, 1973). Elephants frequently broke out of their protected area, and this resulted in many deaths. Seven mature elephants and two calves were shot by farmers in retaliation for the damage they caused whilst on the farmers' land, and two elephants were involved in fatal collisions with trains whilst outside the park.

An elephant-proof fence was constructed in 1954, and comparison of growth and mortality rates before and after completion of this fence enables assessment of the impact of inadequate fencing on the population. Population mortality prior to the fencing of the park is significantly higher than mortality after 1954, when the elephants were securely confined (Fig. 1; 1931-1953 mean mortality $=5.0 \%, \mathrm{SD}=6.2 ; 1954-1998$ mean mortality $=$ $1.2 \%, \mathrm{SD}=1.4$; Mann-Whitney $U=0.00, P=0.003$ ). In addition, the population's annual growth rate prior to the fencing of the park is significantly lower than the observed annual growth rate after the completion of the elephant-proof fence (1931-1953 annual growth rate = $3.2 \%, \mathrm{SD}=11.1 ; 1954-1998$ annual growth rate $=6.1 \%$, $\mathrm{SD}=3.7$; Mann-Whitney $U=340.5, P=0.029)$.

\section{Confinement of the population, 1954-1998}

The original elephant-proof fence, completed in September 1954 , confined the population within an area of $22.7 \mathrm{~km}^{2}$. Between 1954 and 1998, the elephant area was enlarged on four occasions (1976, 1982, 1984 and 1992) to a final size of $103 \mathrm{~km}^{2}$. During this time population size increased from 22 to 284 elephants (Fig. 1).

Population density during 1954-1998 was 1.02-4.01 elephants $\mathrm{km}^{-2}$. Multiple regression analyses show no indication of density dependence acting upon the population's recruitment rate since the fencing of the park. Annual rainfall data from 1955 to 1996 (obtained from the Agricultural Research Council Institute for Soil, Climate and Water) were incorporated into the analysis because elephant conception rate is known to be influenced by rainfall (Moss, 2001). Results showed conception rate in Addo to be significantly correlated to rainfall (1955-1996 data: $\beta=0.343, P=0.039)$, but no significant correlation was observed between conception rate and population density (1955-1996 data: $\beta=-0.0316, P=0.85)$. 

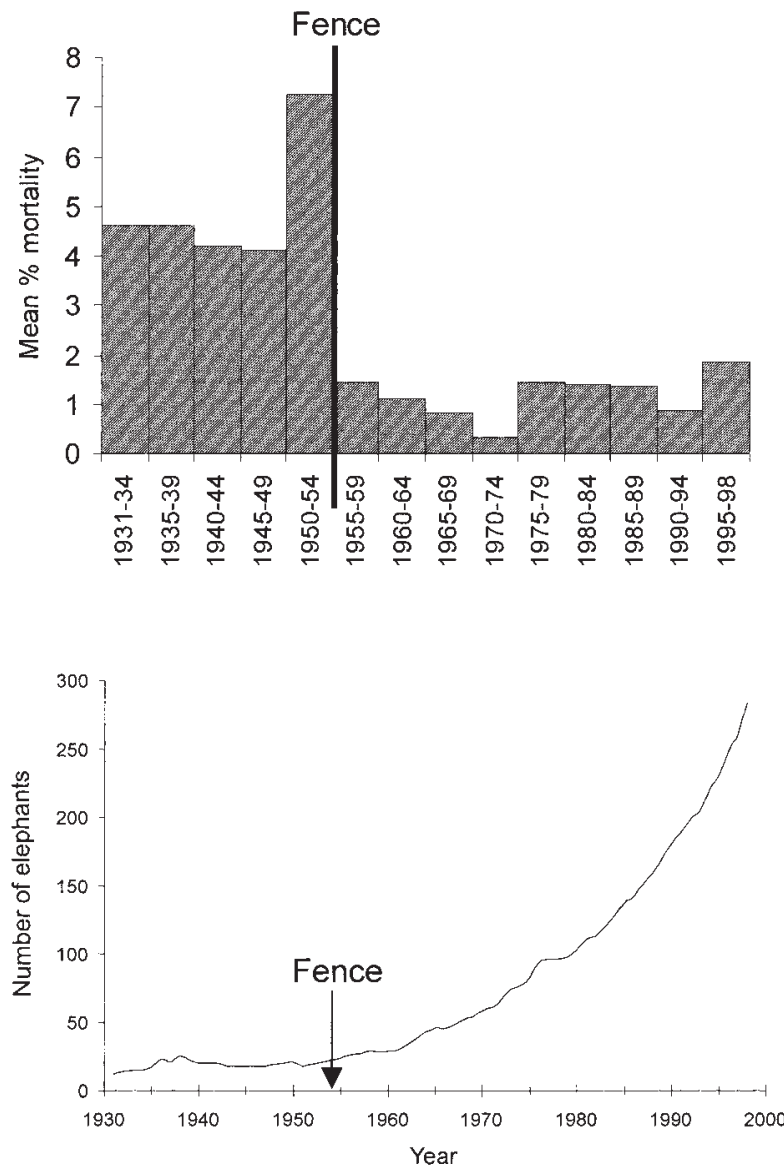

Fig. 1 Mean Addo elephant population mortality (upper) and population size (lower), 1931-1998. Mortality for the population as a whole was calculated as a percentage of the population size for each year. Mean mortalities, calculated for blocks of five years, are illustrated (with the exception of the first and last bars, which represent periods of four years each). Population sizes are derived from reconstructed annual population estimates (Whitehouse \& Hall-Martin, 2000). The date of fencing of the park is indicated.

Demographic analyses conducted on males and females separately reveal marked sexual differences in survival and mortality since the fencing of the park. The sex ratio of newborn calves does not differ significantly from 1:1 (1954-1998 births: 157 males: 163 females; $\chi^{2}=0.11$, $P>0.05$ ), but adult ( $>12$ years of age) sex ratio is significantly female biased (49 males: 75 females at end of 1998; $\left.\chi^{2}=5.45, P<0.05\right)$. Mortality rates for calves in their first year are similar for both sexes, but thereafter male mortality rates are higher than those of females in all age classes (Table 1). As a result of this high male mortality, the oldest age classes comprise females only (oldest female in the park $=60$ years of age, oldest male $=44$ years; Fig. 2), and survival curves show a sharp contrast between male and female elephants within AENP (Fig. 3).
Table 1 Age-specific mortality for the Addo elephant population, 1976-1998. Mortality rates were calculated for each year class (males and females considered separately) as the percentage of the total number of animals entering the year class between 1976 and 1998 who died before reaching the next year class. Mean mortality rates are given for grouped age classes.

\begin{tabular}{lcr}
\hline & \multicolumn{2}{l}{ Mortality rate\% } \\
\cline { 2 - 3 } Age class (years) & Male & Female \\
\hline 0 & 6.2 & 6.2 \\
$1-9$ & 0.9 & 0.1 \\
$10-19$ & 2.0 & 0.4 \\
$20-29$ & 3.1 & 0.3 \\
$30-44$ & 5.1 & 1.2 \\
$45-59$ & 100 & 1.6 \\
$60-63$ & & 100 \\
\hline
\end{tabular}

The causes of mortality amongst adult males and females before and after the fencing of the park were compared (Table 2). Throughout 1931-1954 a minimum of $80 \%$ of all deaths could be attributed to problems encountered by the elephants whilst outside the park (hunting, train accidents, and other incidents) and, therefore, can be related to the lack of a fence. During this period there were no reported deaths caused by natural sickness or injury, old age, or intraspecific fighting among adults.

Following the secure fencing of the park the majority of adult cows have died of natural causes (Table 2). The primary cause of death amongst adult bulls, however, is intraspecific fighting, with a minimum of $70 \%(14 / 20)$ of adult males who have died since 1954 being killed in this manner. A further four adult males that died of unknown causes might also have been killed in fights, because there are no records of any sicknesses or injuries prior to the disappearance of these bulls, and none were old enough to have died of old age. Therefore, it is possible that up to $90 \%$ of the deaths of adult males since the fencing of the park are caused by intraspecific fighting.

Although lower survival of male elephants in comparison to females has been reported elsewhere (Moss, 2001), the frequency of intraspecific fights leading to the death of Addo bulls is unusually high. Whilst sparring is common amongst all male elephants, and is necessary for them to establish and maintain their position in the male dominance hierarchy (Poole, 1982; Moss \& Poole, 1983), in natural populations "records of elephants dying in fights with one another are few and far between" (Hanks, 1979). This is expected from an examination of the theory of animal conflicts, which shows that fights between conspecifics should rarely result in serious injury (Maynard Smith \& Price, 1973). 


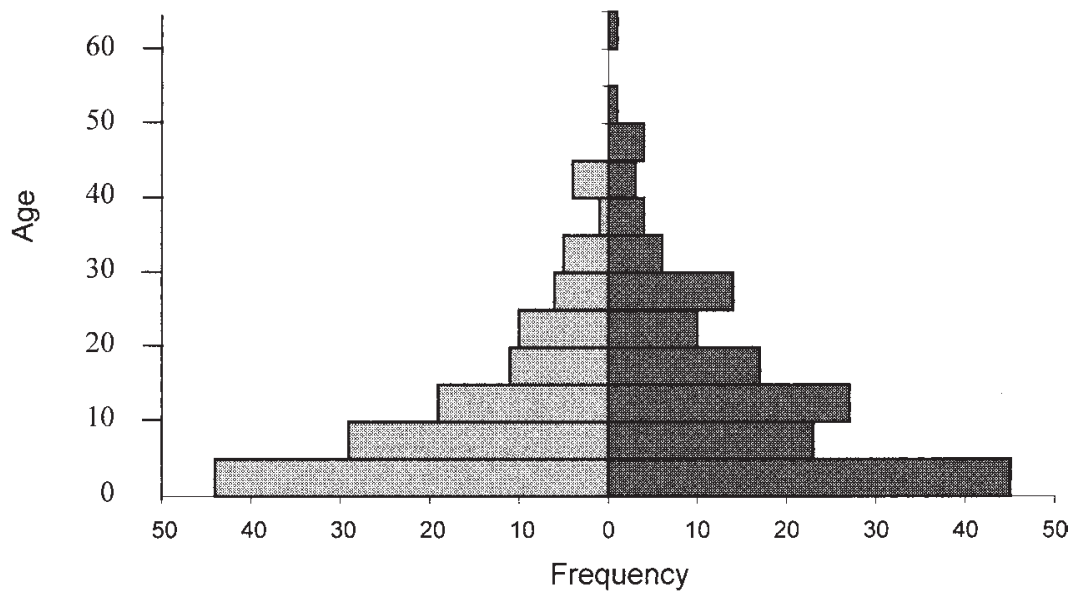

Fig. 2 Age pyramid of the Addo elephant population, December 1998. Elephants are grouped into five-year age classes, with males (pale grey) and females (dark grey) given separately.

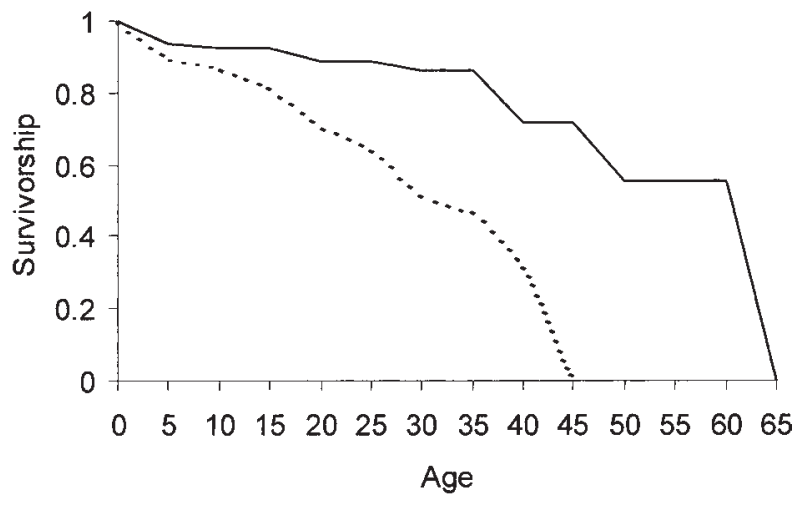

Fig. 3 Survival curves for male (dashed line) and female (solid line) elephants within the AENP, based on population data between 1976 and 1998.

Table 2 Number of adult ( $>12$ years of age) male and female Addo elephants who died of different causes before and after construction of the elephant proof fence in 1954.

\begin{tabular}{lccccc}
\hline & \multicolumn{2}{l}{ Pre 1954 } & & \multicolumn{2}{l}{ Post 1954 } \\
\cline { 2 - 3 } \cline { 5 - 6 } Cause of death & Male & Female & & Male & Female \\
\hline Man induced - outside park & 3 & 6 & & 0 \\
Man induced - inside park & 2 & 0 & & 1 & 1 \\
Natural sickness/injury & 0 & 0 & & 1 & 3 \\
Old age & 0 & 0 & & 0 & 6 \\
Intraspecific fighting & 0 & 0 & & 14 & 1 \\
Unknown & 0 & 0 & & 4 & 2 \\
\hline
\end{tabular}

\section{Discussion}

Retrospective assessment of the consequences of past management practices can provide useful lessons for improvement of our understanding of species and how best to manage them. It is apparent from the three case studies that the management of the Addo elephant population was based on decisions made to fulfil specific and immediate perceived needs, such as to remove problem animals and to prevent elephants leaving the park. However, it appears that little thought was given to the possibility of broader or long-term ramifications of management interventions, and negligible effort was made to monitor the effects of applied management.

In AENP, the deliberate removal of both sexually mature founder males not only hindered early population growth, but also considerably increased the threats to the population's persistence at a time when the population was already at risk due to its small size (Goodman, 1987; Foose \& Ballou, 1988; Caughley, 1994). Looked at in isolation, the incidences in which the two bulls were destroyed may appear justifiable. Shooting them probably appeared to be the only solution to the unacceptable problems of expensive damage to crucial windmills by one bull, and loss of human and elephant life caused by the other bull. However, when considered in the light of the objectives of the newly proclaimed park (to preserve the last surviving elephants in the area), and the size and composition of the population at the time, the wisdom of these management decisions appears questionable. In those days it was not possible to translocate male elephants from elsewhere to enhance the population's chances of survival, and if no male calves had been born during the early 1930s, or if none had survived to maturity, the population would not have survived. This case study highlights the importance of forethought and evaluation of alternative management decisions prior to implementation.

Poor management is not always a manifestation of inappropriate action, but can also be a result of absence of appropriate action. In Tsavo National Park, Kenya, the laissez-faire policy adopted during the 1960s for management of the elephant population has been subject to considerable debate, and is believed by some to have been 
misguided and inappropriate (Parker, 1983; Waithaka, 1997). In AENP, the lack of construction of a secure boundary fence prior to 1954 resulted in high elephant mortality and seriously decreased the population's initial rate of recovery. Protection of elephants that are coming into conflict with humans cannot be achieved by giving the animals protected status on paper or geographically; a secure barrier between the elephants and humans is needed.

Although Addo's elephant population as a whole appeared to respond favourably to the fencing of the park, analyses of the two sexes separately revealed a negative influence of confinement on the natural behavioural patterns and survival of the males. As wildlife habitats diminish and fragment, and protected areas more frequently need to be fenced, an increasing number of elephant populations will be found within relatively artificial environments (Ebedes et al., 1995; Waithaka, 1997). It may therefore be necessary to question how such environmental conditions influence behaviour, and how populations can be managed to conserve natural behavioural patterns. Although a number of carrying capacities for elephants have been previously described (e.g. Lindsay, 1993), none of these have taken behavioural needs into consideration. Yet, evidence suggests that under current conditions, a 'social carrying capacity' for the male elephants within AENP might have been exceeded. Future management should perhaps incorporate behavioural conservation and the concept of 'social carrying capacities', with the needs of males and females evaluated separately.

As this case study highlights, we still do not fully understand how best to manage elephants. Whilst we may be able to identify past management decisions that, with hindsight, appear inappropriate, we do not have all the answers. Today's managers need to acknowledge that in several decades time increased understanding may enable scientists to look back critically at their management decisions. Therefore, to ensure a continual process of learning and improvement of management strategies, conservation management and research must be treated as necessary partners. Monitoring should be an integral part of the implementation of any management plan and, because we do not know a priori how a population will respond to management, this monitoring needs to be as broad as possible.

\section{Acknowledgements}

This research was funded by South African National Parks (SANP), the International Fund for Animal Welfare (IFAW), and the National Research Foundation.
Additional thanks to SANP and Dr Anthony Hall-Martin for assistance with accessing historical records; and to IFAW for provision of a vehicle and computer equipment.

\section{References}

Bell, R.H.V. (1983) Decision-making in wildlife management with reference to problems of overpopulation. In Management of Large Mammals in African Conservation Areas (ed. R.N. Owen-Smith), pp. 145-172. University of Witwatersrand, Johannesburg.

Caughley, G. (1994) Directions in conservation biology. Journal of Animal Ecology, 63, 215-244.

Dublin, H.T. \& Taylor, R.D. (1996) Making management decisions from data. In Studying Elephants. AWF Technical Handbook Series 7 (ed. K. Kangwana), pp. 10-17. African Wildlife Foundation, Nairobi.

Ebedes, H., Vernon, C. \& Grundlingh, I. (1995) Past, present and future distribution of elephants in southern Africa. In Proceedings of a Symposium on the African Elephant as a Game Ranch Animal (eds J. van Heerden \& B.L. Penzhorn), pp. 1-13. South African Veterinary Association Wildlife Group, Berg-en-dal, Kruger National Park.

Foose, T.J. \& Ballou, J.D. (1988) Management of small populations. International Zoo Yearbook, 27, 26-41.

Garai, M.E. (1997) The development of social behaviour in translocated juvenile African elephants Loxodonta africana (Blumenbach). PhD thesis, University of Pretoria, Pretoria.

Goodman, D. (1987) The demography of chance extinction. In Viable Populations for Conservation (ed. M.E. Soule), pp. 11-34. Cambridge University Press, Cambridge, UK.

Hall-Martin, A.J. (1992) Distribution and status of the African elephant Loxodonta africana in South Africa, 1652-1992. Koedoe, 35, 65-88.

Hanks, J. (1979) A Struggle for Survival: The Elephant Problem. Struik, Cape Town.

Hoare, R. (2001) Management implications of new research on problem elephants. Pachyderm, 30, 44-48.

Hoffman, M.T. (1993) Major P.J. Pretorius and the decimation of the Addo elephant herd in 1919-1920: important reassessments. Koedoe, 36, 23-44.

Lindsay, K. (1993) Elephants and habitats: the need for clear objectives. Pachyderm, 16, 34-40.

Macnab, J. (1983) Wildlife management as scientific experimentation. Wildlife Society Bulletin, 11, 397-401.

Maynard Smith, J. \& Price, G.R. (1973) The logic of animal conflict. Nature, 246, 15-18.

Moss, C.J. (2001) The demography of an African elephant (Loxodonta africana) population in Amboseli, Kenya. Journal of Zoology, London, 255, 145-146.

Moss, C.J. \& Poole, J.H. (1983) Relationships and social structure of African elephants. In Primate Social Relations (ed. R.A. Hinde), pp. 315-325. Blackwell Scientific Publications, Oxford.

Parker, I.S.C. (1983) The Tsavo story: an ecological case history. In Management of Mammals in African Conservation Areas (ed. R.N. Owen-Smith), pp. 37-49. University of Witwatersrand, Johannesburg. 
Poole, J.H. (1982) Musth and male-male competition in the African elephant. PhD thesis, University of Cambridge, Cambridge, UK.

Pringle, J.A. (1948) Future of Addo Elephant Park depends on fence. African Wildife, 2, 19-24.

Pringle, J.A. (1973) The Addo elephants and the Armstrong fence. Eastern Cape Naturalist, 48, 1-4.

Slotow, R., van Dyk, G., Poole, J.H., Page, B. \& Klocke, A. (2000) Older bull elephants control young males. Nature, 408, 425-426.

Waithaka, J. (1997) Management of elephant populatons in Kenya. Pachyderm, 24, 33-36.

Whitehouse, A.M. \& Hall-Martin, A.J. (2000) Elephants in Addo Elephant National Park, South Africa: reconstruction of the population's history. Oryx, 34, 46-55.

\section{Biographical sketches}

Anna Whitehouse (nee Woodd) graduated in zoology at the University of Cambridge, UK, in 1994, and was awarded her PhD by the University of Port Elizabeth in 2001. Her research focused on the Addo elephants, including aspects on the population's history, demography, behaviour and genetics. She is currently working as a consultant, and continues to be involved in research on the Addo elephant population and elephants elsewhere, as well as related conservation and education work.

Graham Kerley is Director of the Terrestrial Ecology Research Unit and an Associate Professor in the Zoology Department at the University of Port Elizabeth. He obtained his MSc at the University of Pretoria and his $\mathrm{PhD}$ at the University of Port Elizabeth. His research centres on sustainable use of natural resources, animal-plant interactions and conservation biology and planning. 